\title{
Experimental Psychology and the Practice of Logic
}

Charles S. Peirce and the Charge of Psychologism, 1869-1885

\section{Claudia Cristalli}

\section{(2) OpenEdition}

\section{Journals}

Electronic version

URL: http://journals.openedition.org/ejpap/1006

DOI: 10.4000/ejpap.1006

ISSN: 2036-4091

Publisher

Associazione Pragma

Electronic reference

Claudia Cristalli, « Experimental Psychology and the Practice of Logic », European Journal of Pragmatism and American Philosophy [Online], IX-1 | 2017, Online since 22 July 2017, connection on 11 June 2020. URL : http://journals.openedition.org/ejpap/1006 ; DOI : https://doi.org/10.4000/ejpap. 1006

This text was automatically generated on 11 June 2020.

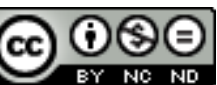

Author retains copyright and grants the European Journal of Pragmatism and American Philosophy right of first publication with the work simultaneously licensed under a Creative Commons AttributionNonCommercial-NoDerivatives 4.0 International License. 


\section{Experimental Psychology and the Practice of Logic}

Charles S. Peirce and the Charge of Psychologism, 1869-1885

Claudia Cristalli

\section{Introduction}

1 Charles Sanders Peirce was acknowledged by William James as the founder of pragmatism, and both Peirce and James are regarded today as "classical pragmatists;" however, while James' appreciation for psychology is widely acknowledged, the role of psychological inquiry in Peirce's thought remains largely unexplored. Few excellent studies indicate Peirce as the first American experimental psychologist (Cadwallader 1974, 1975; Fisch 1986) and as the first to perform a truly modern experiment in psycho-physics (Hacking 1988). Nonetheless, Peirce's commitment to psycho-physics fails to be fully integrated with the broader project of his philosophy, and scholars mostly focus on reassuring the reader that Peirce is not committed to psychologism in any form. Indeed, there is a difference between studying psychology and using its results on the one side, and deriving one's philosophy and logic from psychological descriptions of the mind. As De Tienne (1996), Colapietro (2003), and Bellucci (2015) note, admitting that Peirce engages in psychological research does not mean to assume a psychologistic attitude towards his philosophy.

2 But what is psychologism exactly, and why should it be avoided? "Psychologism" designs the philosophical attitude that regards the processes of knowing and meaning as explainable, first and foremost, via psychological laws. Consider these two questions: 1

1) How do we reason?

2) How ought we to reason in order to reason correctly?

3 The first question is usually considered to be a question in psychology or neuroscience; it refers to reasoning as a process which occurs in the mind or brain quite independently of our intentions. The second in contrast is a question about reasoning 
as a conscious activity which can be judged right or wrong. It is a question in logic. The problem of psychologism is the problem of the relation between 1) and 2), i.e. between the psychological and the logical aspects of thought. This problem can be further articulated in a second set of questions:

3) Are the laws according to which we reason also the laws according to which we ought to reason?

4) Do we need to model our normative prescriptions on a descriptive account of the mind?

If you are a strong anti-psychologist, you will want to answer 3) and 4) with a resolute "no."

4 Historically, the question of psychologism developed as a corollary of the problem of the status of logic. Peirce denied that logic should be based on psychology (in fact, in his numerous classification of the sciences, psychology follows logic) and claimed that the laws of logic were different and independent from those of psychology. As is apparent from the 1865 Harvard Lectures and from the 1866 Lowell Lectures, Peirce defended a thoroughly un-psychologistic logic from the very beginning of his carreer. ${ }^{2}$ However, Peirce's position appears less clear cut in the years 1868-85, which are also the years in which Peirce elaborates and defines his philosophy and his semiotics and in which he builds his fame as a logician. The 1877 "The Fixation of Belief" paper, where Peirce introduces the notions of "doubt" and "belief" to explain inquiry, is possibly seen as the most controversial writing of this period. Murphey sees in the concepts of doubt and belief a danger to the whole architectonic project of philosophy; ${ }^{3}$ Hookway (1993a, 1993b) tries to save a space for "feelings" in science and epistemology, ${ }^{4}$ while Misak (1991) is worried that the notion of truth be relative to those feelings and ultimately useless, since its reach is anyway deferred to "the long run." Kasser (1999) reports that the whole Illustrations series, as well as the 1868 papers, are considered by most scholars as "thoroughly psychologistic." ${ }^{5}$ His attempt at dealing with belief and doubt involves tiding them back to common sense. ${ }^{6}$ In this essay, I would like to unpack a bit more the charge of psychologism moved against Peirce by examining it through the specific form that psychology took in the nineteenth century. While many scholars endorse an historical approach to Peirce's thought, and while all recognise him as a versatile man of science, difficulties in Peirce's philosophy are rarely examined with recourse to his practice of science. My claim is that the ambiguities surrounding Peirce's psychologism could be dispelled - at least for the time frame 1868-85 - in the context of Peirce's engagement with experimental psychology. Such a reconstruction shows that a descriptive account of the human faculties may well support Peirce's normative ambition without having to provide a ground for them. The argument is articulated as follows:

5 Firstly, Peirce's early appreciation of experimental psychology appears from his early reading of Fechner and Wundt, while the 1868 essays "On A New List of Categories" and "Questions Concerning Certain Faculties Claimed for Man" show psychologically informed arguments in support of the thesis that all cognition is inferential. Second, the epistemological legitimacy of empirical psychology is traced back to Kant's section on the "Anticipations of Perception" in the first Critique and to some of its nineteenth century influences. Fechner was among them, and the third and fourth paragraphs deal with the use that Peirce makes of Fechner's psychophysical law in his astronomy research $(1878)$ and in his logic of science $(1869,1877-78)$ respectively. Experimental psychology is for Peirce a science just as all other sciences are. Therefore, its results 
can and should be taken into account for the elaboration of good standards of logical practice, despite the fact that they do not constitute a justification of it. Fifth, I examine how Peirce challenges Fechner's law with a psychophysical experiment of its own. The law that Peirce and Jastrow propose is actually a better fit into Peirce's theory of inquiry and sheds some light on what we may expect from Peirce's concepts of reality and truth.

\section{The Origins: Peirce's Early Appreciation of Psychology}

6 Among the classical pragmatists, it is usually William James who is associated with psychology. Charles Sanders Peirce is instead introduced as a logician and a versatile scientist, whose chief interests laid in logic, mathematics, and in a somehow unpopular metaphysics. Nonetheless, Peirce was also a practitioner of psychology in its most experimental form, namely as the measurement of stimuli response and intensity of sensation. In this field, Peirce's greatest accomplishment is constituted by the paper "On Small Differences of Sensation" (1885), written with Joseph Jastrow while teaching part-time at Johns Hopkins University. Because of the methodological improvements introduced in experimental psychology, ${ }^{7}$ the paper is usually read as yet another example of Peirce's versatile genius, and its content fails to be related to Peirce's broader logical and philosophical inquiry. Despite this, the 1885 paper triggered some interest in Peirce's psychological commitment from both a history of psychology and a pragmatist perspective.

7 In the field of psychology, Cadwallader $(1974,1975)$ gently reclaimed Peirce as the first American experimental psychologist, a claim later confirmed by Fisch (W3: xxvii). Peirce's first published psychology paper is his 1877 paper "Note on the Sensation of Color" (W3: 211-6), and, as the editors of the Writings report, Peirce was carrying on founded psychological research as early as $1875 .{ }^{8}$ The Note on color had a certain diffusion, since it was published both in the U.S. and in the U.K.; 9 Peirce moreover was acquainted with experimental psychology through the work of Wundt and Fechner at least since $1869 .{ }^{10}$ From Wundt Peirce got the permission to translate the Vorlesungen über Menschen- und Thierseele [Lectures on the Animal and the Human Mind] in 1869. In July of the same year, Peirce wrote to his father Benjamin a note accompanying his copy of Fechner's Elemente der Psychophysik [Elements of Psychophysics], where he singled out for his father's attention the methodological sections of the book, i.e. Fechner's exposition of the "Methode der richtigen und falschen Fälle" [Method of right and wrong cases] and the "Methode der mittleren Fehler" [Method of the average error]. ${ }^{11}$ Those two statistical methods were developed to corroborate Fechner's famous psychophysical law, also known today as the "just noticeable differences" (jnd) law or as the Weber-Fechner Law: an equation stating that the intensity of a perceived sensation $S$ is proportional to a constant $k$ times the logarithm of the intensity of the given stimulus $I$. In lay words, Fechner's law instituted a relation between the intensity of a physical quality, i.e. brightness or pitch or weight, and the intensity of a psychical one, i.e. the sensation occasioned by the stimulus. A constant $k$ was introduced to model the experimental finding that an increase in the stimulus does not immediately translate into an increase in sensation. To actually cross the threshold of sensation, the stimulus has to be augmented of a fixed amount $k$. The constant can be visualised as a 
step before the threshold, and the whole process of perceiving becomes a step-like function if plotted on a graph. The concept of a threshold in sensation is practically useful, since it allows to read a change in sensation in unit-like degrees, similarly to how a change in temperature can be read along a thermometer. The concept of threshold also allows to think that there is more going on in the interaction between stimuli and sensory organs than what actually appears in sensation, thus undermining the well-established belief that knowledge of our sensations is something immediate and simple.

Peirce is most interested in arguing against the idea of immediacy in sensation, since immediate knowledge by definition could not be improved or refuted by future cognition. Immediate knowledge would mean that every subject has a direct, intuitive cognition of her objects; the ultimate warranty for knowledge would not be found anywhere but in the subject's conscience. The rejection of intuitive knowledge is thoroughly carried out in the 1868 paper "Questions Concerning Certain Faculties Claimed For Man," where Peirce defines the privilege accorded to the individual subject by the intuitionist model of knowledge as "the happy device of considering the enunciations of authority to be essentially indemonstrable." ${ }^{12}$ Such an epistemic model is opposed with arguments coming from the history of philosophy, from pedagogy and common sense experience, as well as from experimental psychology. As psychology teaches, for the sensation to occur it is necessary that the stimuli be compared, therefore, cognition cannot be attained through an immediate act of intuition, and Peirce brought examples from daily life as well as from sensory experiments to make his case against introspectionism. It is not sure whether Peirce had read his Fechner in 1868; as we are going to see, he does not make any use of the concept of threshold at this point, but uses examples from experimental psychology extensively in his philosophical writings and speculates on the mechanism which allows sensations to be manifest in consciousness at all.

In the following, I highlight Peirce's use of empirical psychology in two papers which he himself would regard as his two best accomplishments in philosophy: ${ }^{13}$ the already mentioned "Questions Concerning Certain Faculties Claimed For Man" and the "On a New List of Categories," which is regarded today as the foundational paper in modern semiotics. ${ }^{14}$ That Peirce's philosophical theory also concerns the problem of how perception could be satisfactory represented in judgment is something on which Peirce scholars seem to agree, as the editors' comment in the second volume of the Writings suggests:

Presenting the categories in close conjunction with his theory of signs and of perceptual judgment, the New List is the culmination of a ten-year effort and the keystone of the American Academy series and indeed of Peirce's (early) philosophy as a whole. ${ }^{15}$

Nonetheless, the distinct contribution that experimental psychology bears on Peirce's notion of perceptual judgement has yet to be assessed, together with the consequences of the use of experimental psychology in philosophy.

In the Faculties paper, Peirce aims at shaking some deep-rooted assumptions about human knowledge, among which the belief that we have an intuitive cognition of our inner states. If this was the case, Peirce argues, we would be fully transparent to ourselves, i.e. we would be able to know ourselves immediately and by some kind of "contemplation." Instead, every knowledge which appears as immediate to our consciousness is the outcome of a process which was either unconscious or distant in 
time. The Faculties paper aims at unmasking the inferential nature of our established beliefs through the exhibition of the process which produced them, as in the case of a child learning its mother tongue, or of the overlap of memory and inference when witnessing in court. Alongside ordinary life examples Peirce makes use of cases from perceptual experiences and experiments. The possibility of basing arguments on sensory analogy is introduced through a reflection over Berkeley's 1709 An Essay towards a New Theory of Vision:

There can be no doubt that before the publication of Berkeley's book on Vision, it had generally been believed that the third dimension of space was immediately intuited, although, at present, nearly all admit that it is known by inference. We had been contemplating the object since the very creation of man, but this discovery was not made until we began to reason about it. ${ }^{16}$

12 All routine perception, including that of spatial depth, which generally is regarded as given, is in fact a product of inference, whose process is not perceived and which appears therefore as an immediate result of experience. Reasoning involves mediation, and this mediation requires that the object be not given in contemplation. This thesis is exemplified by Peirce through the case of tactile perception, where feeling a piece of cloth actually requires the comparison of different moments of the experience of the piece of cloth and the comparison is achieved by moving one's hand over it:

A man can distinguish different textures of cloth by feeling; but not immediately, for he requires to move his fingers over the cloth, which shows that he is obliged to compare the sensations of one instant with those of another. ${ }^{17}$

The cognitive operation performed, albeit unconsciously, is that of comparison. Each conscious sensation is produced - according to Peirce's experimental psychology - by summoning and comparing different stimuli. Accordingly, from this empirical example of stimuli comparison in sensation Peirce moves to illustrate his thesis with an experimental case based on tone perception. While in the case of the tactile feeling the reader can imagine a perfectly still finger which receives a point-like stimulus from which it can infer a presence but not discriminate a texture, in the case of tone perception Peirce does not rely on common-sense experience but rather on the physical definition of tone and on the physical mechanism of hearing:

The pitch of a tone depends upon the rapidity of the succession of the vibrations which reach the ear. Each of those vibrations produces an impulse upon the ear. [...] these impressions must exist previously to any tone; hence, the sensation of pitch is determined by previous cognition. Nevertheless, this would never have been discovered by the mere contemplation of that feeling. ${ }^{18}$

14 To show that something is indeed determined by something else - here, the sensation of pitch by a "previous cognition" - means to show that the immediately perceived content of sensation is indeed a result, and not a first indubitable starting point of cognition. For Peirce, cognition, at every level, is always the product of inference, and the basic structure of rational thought is already at work, albeit unconsciously, in sensation. Empirical research in this context is used to illustrate and support a radical philosophical thesis: that all knowledge is mediated and the product of some previous cognition; and that to talk of an absolute start or first cognition is both intellectually and perceptually unintelligible.

In the 1868 On a New List of Categories, Peirce introduces his theory on the inferential structure of knowledge as a well-established scientific fact:

§ 8. Empirical psychology has established the fact that we can know a quality only

by means of its contrast with or similarity to another. ${ }^{19}$ 
Comparison and inference from previous experiences is essential not only for the appearance of a certain quality in sensation, but also for our conscious acknowledging it. Relying as it seems on the results of empirical psychology, Peirce in this sentence opens up the possibility of a psychologistic interpretation of his whole philosophical project, since experimental psychology plays not only an explanatory role, but a constitutive one. It is from the finding of empirical psychology that Peirce moves to argue that all quality is known only by comparison, either by similarity or by contrast. Peirce however must have been aware of the consequences of psychologism and was not sure that relying on psychology for developing his argument was a wise thing to do, as a note in MS 152 (1868) shows:

It may be doubted whether it was philosophical to rest this matter on empirical psychology. ${ }^{20}$

While doubting the legitimacy of his proceeding, Peirce confesses it; however, before dismissing the whole philosophical argument as "psychologistic," one has to look at the way in which psychology is in fact used in Peirce's thought. Peirce's project is not based on dragging philosophical arguments from the results of psychological investigation. As it emerges from other sections of the New List, psychology is most relevant for philosophy in virtue of the methodological attitude that it teaches; moreover, it can be performed in the imagination when there is no availability of psychological experiments. Imaginary experiments, i.e., mental experiments, can thus lead to wellformulated "examples" which can elucidate philosophical concepts, as in the case of "correlate":

$\S 9$. The occasion of reference to a correlate is obviously by comparison. This act has not been sufficiently studied by the psychologists, and it will, therefore, be necessary to adduce some examples to show in what it consists. ${ }^{21}$

A correlate is just something which is in a relation with something else; the particular respects in which the two are related become apparent through comparison. Peirce uses two examples of comparison at work in the imagination. The first illustrates how reference occurs through the mental perception of similarities and differences:

Suppose we wish to compare the letters $p$ and $b$. We may imagine one of them to be turned over on the line of writing as an axis, then laid upon the other, and finally to become transparent so that the other can be seen through it. In this way we shall form a new image which mediates between the images of the two letters, inasmuch as it represents one of them to be (when turned over) the likeness of the other. ${ }^{22}$

19 The mental comparison Peirce describes involves rotating, translating, and mapping one of the objects upon the other: a standard procedure in geometry, which is employed to the assessment of relations of similarity or dissimilarity between two or more figures. ${ }^{23}$ To this, Peirce adds the creation of a third image which actually mediates between the first two. A discussion of the role of this third image in Peirce's system of categories would bring us astray; here I only wish to stress how this third image, which is the result of a process enabling to perceive similarity in imagination, performs the logical function of conveying the meaning of the comparison, i.e. of spelling out precisely in which relation the two figures stand.

Eventually, Peirce is using psychological results and techniques in creating a new branch of philosophy (semiotics) which must be utterly independent from the psychologistic belief that meaning can be ascertained through introspection. Psychologism as introspectionism or subjectivism is clearly ruled out from Peirce's philosophy; more complex is the role played by experimental psychology. On the one 
hand, using experimental psychology to justify philosophical claims can be an illegitimate step, which possibly undermines the very foundations of Peirce's logical project; on the other hand, his arguments are symmetrically defended also from a philosophical standpoint and involve reasoning about being and substance, qualities, relations, and performing a logical analysis of the very processes of thought. The question is whether such an interplay between logic and psychology can be justified, and I address it in the following sections through a reconstruction of experimental psychology's philosophical background in the nineteenth century Germany, where it took the name of "psychophysics," i.e., physics of the soul. Psychophysics raised a wide range of questions spacing from scientific method to metaphysical speculations. The idea that an inferential, scientific account of the first moments of knowledge was attainable is closely related with the post-Kantian discomfort with any idea of limits or borders to knowledge. In Peirce's seminal writings of 1868, the ambiguity between the logical and the psychological standpoint is accrued by experimental psychology actually exhibiting a logical trait: that of an unconscious inference. Experiments thus show how the powers of inference can be stretched to the very beginning of knowledge, where sensations and their qualities are assembled from a multitude of stimuli.

\section{The Background: On Some Philosophical Reasons to do Psychology by Degrees}

21 Psychophysic as an autonomous discipline was born and thrived in the nineteenth century, mostly in post-Kantian circles; indeed, it was one of the outcomes - along with Idealism and Naturphilosophie - of the challenge posed by critical thought. The core idea of psychophysics was that it is possible to treat psychical phenomena as scientifically as the physical ones, i.e. they both can be measured and compared according to an overarching scale. This idea had to deal with Kant's famous dismissal of the possibility of psychology as a science ${ }^{24}$ and had to prove that psychical phenomena can be consistently interpreted quantitatively. Moreover, psychophysics carried additional metaphysical commitments about how the psychical and the physical are related: either as distinct but communicating vessels, or as one nature with different manifestations. While it is usually assumed that psychophysics moves out of philosophy into becoming a science, its philosophical foundation in Kant can be traced back to the scientific work in photometry (the measurement of light brightness) by Johann Heinrich Lambert (1728-77). From the very beginning, as it seems, critical reflection and scientific research go hand in hand.

Attempts at measuring sensation in relation to physical stimuli can be found already in the eighteenth century. ${ }^{25}$ Kant was influenced in the first Critique by the possibility to compare and measure sensations by degrees introduced by Lambert, a natural philosopher who published in many fields, such as mathematics, optics, astronomy, and maps projections. In photometry he studied how the brightness of different lightsources could be compared, ultimately arguing for the possibility to understand brightness as a sum of a certain quantity of brightness, as that which could be expressed by a candle. Concerning psychology, Lambert's influence on Kant involves the possibility of treating mathematically empirical perceptions. In sketching the "System of the Principles of Pure Understanding" (KrV: A148/B187 ff.), Kant illustrates the two principles which deal with the applicability of mathematics to objects of 
experience, i.e. the Axioms of intuition and in the Anticipations of Perception, with an example drawn from Lambert's photometric discoveries: ${ }^{26}$

The preceding two principles, which I named the mathematical ones in consideration of the fact that they justified applying mathematics to appearances, pertained to appearances with regard to their mere possibility, and taught how both their intuition and the real in their perception could be generated in accordance with rules of a mathematical synthesis, hence how in both cases numerical magnitudes and, with them, the determination of the appearance as magnitude, could be used. E.g. I would be able to compose and determine a priori, i.e., to construct the degree of the sensation of sunlight out of about 200,000 illuminations from the moon. ${ }^{27}$

The quality content conveyed by sensations, i.e., "brightness" in the case of light, in as far as it is a quality it is something that can always be experienced only "empirically," i.e. a posteriori (KrV: A175/B217); however, in so far as it can be brought to unity by a consciousness, i.e. to a degree, it constitutes "the real" in perception. What is real is not the quality in itself, nor the degree without quality, which would be nothing but the possibility of the synthetic activity of consciousness. What is real in perception is, for Kant, the quality of sensation as unified into a degree. This unification is performed through the synthetic activity of consciousness, which Kant justifies transcendentally, i.e. claiming it to be among the a priori conditions for having any experience at all. The following generation of post-Kantians interested in psychology will try to assess whether the synthetic activity of consciousness could also be investigated a posteriori, i.e. through experiment. Experimental inquiry was usually considered to be the domain of physical sciences, since only in physics measurement had provided an objective criterion to relate and compare different objects. However, in the Anticipations of perception and in the Principles of pure understanding more generally Kant provided a very convincing case for how mathematics could be applied to the realm of sensation. Intensive magnitudes could also be investigated empirically, since they too could be mathematically constructed and subsequently compared along a scale. In light of these considerations, Fechner's emphasis on psychophysics "as an exact science of the relation between body and mind" in the opening statement of his 1860 Elemente der Psychophysik [Elements of Psychophysics] can be better understood. ${ }^{28}$

While the Preface is the only place in the work where Fechner indulges in making bold philosophical claims regarding "body" and "mind," it nonetheless gives a hint of the metaphysical interests which lay behind his scientific research. Fechner is usually read either from the point of view of his science or from that of his philosophy; an exception to this is Marylin Marshall (1982), who provides an integrated account of the development of Fechner's thought starting with his biography.

In 1820, when still a medical student, Fechner read Lorenz Oken's Lehrbuch der Naturphilosophie [Textbook of Natural Philosophy] and became fascinated by its approach to biological science and by its holistic understanding of organisms. ${ }^{29} \mathrm{Fechner}$ did not stop at Oken, but went on reading Hegel, Schelling and Herbart. In 1824 however Fechner translated Biot's Précis élémentaire de physique expérimentale [Elementary Textbook of Experimental Physics] and decided to have a career in the physical sciences. Biot was one of Laplace's favorite pupils, and his Précis is a book written with the aim to replace qualitative and conversational expositions of physics with rigorous mathematical ones. Precision and quantification were of course Biot's chief concerns, and those values were quickly appropriated by Fechner, as his 
subsequent research show. ${ }^{30}$ However, Fechner's acceptance of Biot's was not uncritical. Contrary to Biot, Fechner kept a place for theoretical knowledge in scientific research, not just as an overarching frame but as the actual guide of hypothesis and consequently of experiments. ${ }^{31}$ Together with this heuristic use of theory, Fechner also showed a strong tendency towards generalisation and integration, be it among different physical theories ${ }^{32}$ or - as it will eventually be - between the physical and the psychical domains. ${ }^{33}$ In pursuing this path, Fechner is clearly following Oken's understanding of philosophy of nature as that discipline that should show the legislative uniformity of its objects:

§13. Now since in Man are manifested self-consciousness or spirit, Physiophilosophy has to show that the laws of spirit are not different from the laws of nature; but that both are transcripts or likenesses of each other. [...] \$17. The whole of philosophy depends, consequently, upon the demonstration of the parallelism that exist between the activities of Nature and of Spirit. ${ }^{34}$ considered both subject to the same legislation; they behave in parallel because they are both compelled by laws, and both sets of laws are accessible to scientific investigation. Oken's main source in thinking the relation between nature and spirit was Schelling, together with alchemy, numerology, and the French intellectual SaintHilaire. ${ }^{35}$ Schelling, as pointed out by Giovanelli (2011: 83-4), incorporates the very details of Kant's formulation of the principle of the Anticipations of Perception in his 1797 essay "Ideas for a Philosophy of Nature" (Ideen zu einer Philosophie der Natur):

[R]eality [Realität] is only felt [gefühlt], is only present in sensation. Yet what is felt [empfunden] is called quality. [...] the real in sensation must be able to increase, or diminish, indefinitely; it must, that is, have a specific degree, though one that can equally well be thought of as infinitely greater, or as infinitely smaller; or, to put it otherwise, between which and the negation of all degree $(=0)$ an infinite sequence of intermediate grades can be imagined. ${ }^{36}$

The degree is thus what constitutes the condition for the manifestation of reality in perception and the structure of reality as experienced in sensation. This structure is an infinite sequence in which each difference - each degree - can be made infinitely small. While this structure is postulated a priori in Kant, Schelling argues for it from an interpretation of the results of experiments in chemistry, magnetism, and electricity (Giovanelli 2011: 82-111). Fechner inherits this composite tradition. Believing in the possibility of a connection between physical and psychical intensities, he develops the experiments and - with the help of the mathematician Wilhelm Weber - the mathematical equation which could make sensation appear as a function of the intensity of the stimulus. This equation was to be known from 1860 onwards as Fechner's law. In it Fechner both affirmed his philosophical interpretation of the mindbody relation and provided a self-contained methodology for a new experimental science of the mind. Of course, it is this second feature which granted him such a lasting success among experimental psychologists. Any scientist could go on performing measurements without paying too much attention to the philosophical scaffolding on which those measurements were built in the first place. They could either pretend to be working without any metaphysical commitment at all, or - as Peirce did - try to accommodate psychology to their own speculations, while at the same time using scientific findings as a chart to navigate philosophy.

European Journal of Pragmatism and American Philosophy, IX-1 | 2017 


\section{Peirce's Use of Fechner's Law: The Photometric Researches (1878)}

Peirce's 1878 Photometric Researches stand out as one of his scientific achievements. In this work, the observational problems related to photometry are addressed also from the point of view of experimental psychology (Fechner's Law) and history, including a report on the historical classifications of celestial bodies starting from Ptolemy's Almagest (1878: 36-55). This is not a baroque show of erudition: historical testimony is restored for the purpose of scientific inquiry, a practice which actually maintains its validity even today, ${ }^{37}$ making astronomy a science which is not as indifferent to history as it is usually assumed among philosophers of science..$^{38}$ In this section, I focus on the contribution that experimental psychology gives to Peirce's scientific research in astronomy. Peirce's use of Fechner's law in the context of photometric observation is not psychologistic but rather respondent to the criteria established by his logic of science, which he was developing precisely in the years of his work at the observatory. One of the fundamental claims of Peirce's logic of science is that logic should teach how to employ methods across the different disciplines. Beyond Fechner's law, Peirce also brought to photometry fresh experimental results from his own research on color perception. Eventually, the Photometric Researches offered Peirce an incredible occasion to test systematically his logic of science upon his scientific practice, as well as to tailor his logic of science to it.

In the Photometric Researches, Peirce reports on a series of observations on the brightnesses of stars and proposed the introduction of a new photometric scale, adjusted according to Fechner's law on perception. The instrument used was a portable telescope known as Zöllner's photometer ${ }^{39}$ which moved from Harvard to Washington together with Peirce as he was temporarily in charge of the Coast Office and as he visited pendulum stations. Zöllner's photometer worked by projecting on the same plate the actual light of the star under observation and an artificial source of light, i.e. a gas flame coming from a Bunsen burner integrated with the telescope structure. The observer could thus compare the brightness of two light sources at one time without moving his eye from one light source to another..$^{40}$ The modifications Peirce suggested did not involve a change in the instrument (as they often did in his measurements of gravity), but rather a different adjustment of the scale along which observations had to be plotted. Peirce proposed that this new photometric scale could deal with errors in observation better thanks to the use of Fechner's law, which provided quite accurate estimations and interpretations of the actual data. There were, of course, limits to this - the first and most serious probably residing in an imperfect fit of predictions with actual observations (1878: 7):

In this way, if Fechner's law were without error as applied to the eye, we should make equal numerical intervals correspond to equal differences of sensation and we should have a scale which would be independent of changes in the transparency of the atmosphere, of differences in the optical powers of our instruments, and of inequalities of visual sensibility. Since Fechner's law is unfortunately not in fact rigidly true, these important conditions cannot in any way be exactly fulfilled, but by making the ratio of light between successive magnitudes equal we at least approximate to their fulfillment $[\text { sic }]^{41}$

30 Fechner law is introduced to account for errors in observation; however, the law itself is not free from error. The relation between errors and observations is not as precise as 
we may wish. Besides, some aspects of perception fail to be accounted by Fechner's law despite influencing our judgement. As Peirce ascertains in his experiment on colors, equally bright colors will appear brighter when warm (i.e., red or yellow), darker when cold (i.e., green or blue); as a consequence of this perceptual fact, it is much more likely to judge a star to be brighter than it actually is (1878: 10). The influence of colors in the perception of brightness is not accounted for by Fechner's law.

The shortcomings of Fechner's law allowed some ground for scepticism on whether the law correctly described the process of sensation. This perplexity pushed Peirce to the hypothesis that the relation between the stimulus intensity and the resulting sensation was in fact a continuous one. In 1883 Peirce designed an experiment to object to Fechner's idea of a fixed threshold of sensation, which I discuss in the next section; its theoretical justification is however already present in his 1878 Photometric Research book:

If a certain force $x$ applied to irritate a nerve produces a certain sensation, there is perhaps no addition to it $\delta x$ so slight that the sensation produced by $x+\delta x$ will not in some slight majority of trials be pronounced more intense than that produced by $x^{42}$

This means that, no matter how small the difference between two sensations may be, it is conceivable that this small difference could indeed influence the subsequent judgement to the point that, if investigation is carried on enough, ultimately the judgement will tend towards the truth. Such a consideration shows how Peirce does not black-box psychology for the purposes of astronomical investigation. While he certainly is using assumptions coming from a different field of inquiry and concerning the relation between external stimuli and sensation, he is not uncritical about the assumptions themselves. In fact, it is a distinctive feature of Peirce's logic of science that truth can be attached provisionally to both pre-existing and incomplete knowledge. Peirce found that Fechner's law was "fully confirmed in various ways" - and its confirmation did not rest upon the perfect accuracy of its predictions, but rather, as it seems, in its explanatory power. This is what justifies its use in photometry:

The reasoning involved in this procedure would be open to criticism if the result were not fully confirmed in various ways. But it is so confirmed; and the (at least, approximate) truth of Fechner's psychophysical law is now fully admitted [...] this is why we do well fix our scale of magnitudes of stars so that equal increments of the numerical magnitude correspond to equal increments in the logarithm of the light. 43

According to Fechner's law, equal changes in the logarithm of the light will have equal effects in our perception of it; therefore, stars should follow a logarithmic progression for what concerns the classification of their magnitude.

\section{Peirce's Use of Fechenr's Law: Its Methodological Justification}

As I hinted before, the justification of Peirce's use in his Photometric Researches of laws and methods coming from different fields (be it psychology or history) resides in his logic of science. Not differently from William Whewell (1794-1866), Peirce also considered logic of science as a method and a guide towards discovery, i.e. towards drawing conclusions which are also justified by facts. In his 1869 drafts on the logic of 
science, "Practical Logic" is what "originated in an attempt to discover a method of investigating truth." ${ }^{\prime 4}$ An historical inquiry into the origins of logic shows it as arising in consequence of a practical need, i.e. that of furnishing reliable methods for inquiry:

In short, we may state it as a historical fact that logic has been essentially the science of the structure of arguments, whereby we can distinguish good arguments from bad ones, can estimate the value of an argument, can determine upon what conditions it is valid, how it needs to be modified, and what can be inferred from a given state of facts. ${ }^{45}$

For this reason, even when inquiry was devoted to the more speculative objects (such as God or God's attributes, as in medieval logic) nonetheless logic retained its practical character. Indeed, logic can be applied to no matter which object, because it has to do with what can be expected or presupposed from certain premises rather than with the nature of the premises themselves.

There is a tension in this account of practical logic, since, on the one hand, logic as the science of the structure of arguments seems fairly removed from its practical or historical content; on the other hand, it is thanks to a certain historical investigation of logic that it emerges as the science of the structure of arguments. The practical nature of logic is not proposed through a deductive, a priori argument, but is argued for through a historical argument on the role that logic played since its invention. Arguments are the different ways in which an inference from a given state of facts can be performed and accounted for. In order to have any practical use at all, however, arguments must have material consequences, i.e. their consequences must contain something which is not already present in the premises:

If the fact expressed in the consequent is the same as that expressed in the antecedent or is a part of it, then the consequence is an empty and meaningless expression [...]. Such a consequence is called formal; but one which expresses a fact concerning the matters in question and not merely concerning the expression of them is termed material. ${ }^{46}$

Peirce then declares that "This distinctions of formal and material consequences is one of the most practically important in the whole range of logic" (W 2: 350). Despite its importance, it is not very clear to what formal logic refers. If formal logic admits only arguments where the content of the consequent is already the content of the antecedent, then only tautologies can be identified as formal consequences. At the same time, both consequences (a) bringing new content not included in the premises and (b) elucidating the relations between terms of the antecedents show some material content. Eventually, since "The investigation of consequences constitutes Logic" (W 2: 349), the investigation of different kinds of consequences will lead to different kinds of logic.

A great part of Peirce's 1869 efforts in "Practical Logic" are to be found in the 1877-78 Illustrations of the Logic of Science. The structure of inquiry as described in the first of those Illustrations, the "Fixation of Belief," consists in the interplay between belief and doubt, which have to be understood as epistemic states rather than as subjective psychological moments. ${ }^{47}$ Indeed, to emphasize the bodily and "external" origin of those states, Peirce draws numerous analogies with physiology, thus suggesting a parallel between the states of inquiry and the physical states of the body:

Doubt [...] stimulates us to action until it is destroyed. This reminds us of the irritation of a nerve and of the reflex action produced thereby; while for the analogue of belief, in the nervous system, we must looked for what are called 
nervous associations - for example, to that habit of the nerves in consequence of which the smell of a peach will make the mouth water. ${ }^{48}$ for thanks to the application of experimental psychology's laws. Psychology offers the means to actually isolate the subjective contributions to knowledge and to reach out for a public object of knowledge: Peirce's program for psychology is therefore oriented in the context of his realist philosophy and of his practical logic of the sciences. However, it must be noted that realism is science's fundamental hypothesis, not science's axiom or postulate. This means that science, in its effort towards objectivity, is constantly in the process of affirming reality as something everyone could ultimately agree upon if the inquiry was pursued long enough. Moreover, experimental psychology is itself a science, and therefore its claim to be able to separate the subjective and the objective in knowledge in virtue of its "laws of perception" must in turn be taken as an hypothesis. In the 1869-78 period, Peirce maintained that Fechner's law was the most convincing form in which the hypothesis of experimental psychology was shaped, and uses it both to establish the real magnitude of the stars and the necessary connection between belief and evidence. However, it is precisely in the context of the Photometric Researches that Peirce found some objections to it, in 
particular for what concerns the idea of the existence of a threshold in perception, i.e. of a discontinuity between the intensity of the stimulus and the intensity of the corresponding sensation. Peirce's objections were formulated as a hypothesis, and they were to be put to test in his celebrated 1885 experiment, "On Small Differences of Sensation."

\section{Fechner's Law Revisited: The 1885 Experiment and its Meaning for Peirce's Philosophy}

In 1885, Peirce published a paper in psychophysics with Joseph Jastrow ${ }^{51}$ (1863-1944), at the time one of Peirce's PhD students, titled "On Small Differences of Sensation." The experiment was planned and run in 1883; the paper was accepted in 1884 and finally published in 1885. The paper has today a niche readership among Peirce scholars, historians of psychology, and statisticians, because of its borderline position among what is now considered science and pseudo-science in psychology and because of the methodological innovations that it contains. As Hacking recognizes (1988), the 1884 experiment was by far the most advanced psychophysical experiment of his time, with randomization and blinding thoroughly implemented for the first time. However, the paper did not enjoy a wide circulation in its own time, and is only briefly mentioned in famous histories of psychology such as Boring's (1942) Sensation and Perception in the History of Experimental Psychology. This could be due also to the fact that the 1884 paper is explicitly set up to refute Fechner's law of psychophysics, a law which remains a standard historical reference even in today's textbooks on the measurement of sensation. Peirce's alternative account of the relation between stimuli and sensations was maybe too obscure, unpractical, or simply not a better tool for prediction than Fechner's. Moreover, Peirce's final proposal that such an alternative way may prove beneficial for the scientific examination of telepathy, one of the highly controversial challenges for psychology at the time, may not have appealed to a scientific community which wanted to get rid of those "unscientific fancies" as quick as possible. ${ }^{52}$ Nonetheless, for the purpose of examining the place of psychological inquiry in Peirce's thought, this experiment is quite relevant.

The core aim of the 1885 experiment was to challenge Fechner's law in two respects. Firstly, it was claimed that the law did not describe the actual relation between intensity in the external stimulus and intensity in sensation, but that it just assessed our ability to discriminate (in judgment) between sensations. Secondly and related to the first, the notion of a threshold in sensation introduced by Fechner's law had to be restricted to conscious sensation only. Since Fechner's results were based on conscious reports of the experienced differences in sensation, nothing prevented sensation to actually change continuously with the change in the stimulus intensity, but to be only perceived as changed after a certain threshold was crossed, i.e. perceived by degrees. From Fechner's experiments, Peirce argues, something could eventually be learned about the ability to make comparisons and the grade of accuracy this ability could possibly reach. However, Fechner's method said nothing about what was actually perceived, or about how the process of perception drew on the received stimuli. From Peirce's epistemological perspective, the possibility to assess what goes on in sensation before judgement means that the laws of perception enable us to account for the subjective distortion of perception in the individual. In challenging Fechner's law, 
Peirce has therefore a philosophical as well as cognitive interest in the possibility of objective knowledge as distinct from its subjective apprehension. Moreover, he wants to move a methodological objection to Fechner and to suggest therefore that his threshold is actually an artifact of Fechner's way of analysing data. Last but not least, Peirce suggests that with his own new method the boundaries of scientific inquiry could be extended as to possibly include the investigation of telepathy. In sum, the main lines of Peirce's criticism of Fechenr's law respond to four distinct but related aims:

Psyco-physical aim: to challenge Fechner's model of discontinuity in perception, or at least to limit its validity to the conscious comparison of stimuli rather than to how stimuli affect, consciously or unconsciously, sensation;

Philosophical aim: to show that the continuity between judgements and sensation is real and that sensations, even unconscious ones, behave inferentially;

Methodological aim: to advance psycho-physics through the employment of methods coming from statistics and probability, especially randomization;

Catchy aim: to have a say in the at the time pervasive debate upon telepathy.

For our purposes, we will focus on 1) and 2) and on their relation. I therefore give a brief account of the experiment and then expand on its implications for Peirce's philosophy and theory of judgements.

The experiment consisted in an exercise in stimuli comparison, with each round incorporating three pressure stimuli. The first and the third stimuli corresponded to the same weight, while the second could be either lighter or heavier according to a certain ratio. Jastrow and Peirce were in turn subjects and observers of their experiments, and they were the only subjects on which the experiment was performed. It took about 5 months of trials, and, in order to take into account the pair's growing expertise and the various adjustments that they were able to introduce as time went on, the trials were grouped into 4 sets and results were compared accordingly. ${ }^{53}$

To inhibit any guessing on the subject's part, the observer was forced by a pack of 25 cards to follow a random order in the sequence of rounds that composed each experimental session. Weights were placed upon a plate, and an ingenuous reworking of a Fairbanks post-office scale ${ }^{54}$ was deployed with the aim of minimizing any potentially disruptive lateral effects (e.g. oscillations, abruptness of the pressure, etc.). The pressure was exerted upon the index finger of the dominant hand of each subject (Peirce was left-handed and Jastrow right-handed). Other precautions were taken in order to prevent fatigue and irritation on the subject's side, and "In this way 150 experiments on each of us were taken at one sitting of two hours." ${ }^{55}$ The subject was forced to answer the question, "which is which?", which is the greater of the two pressures (the one at the beginning and at the end or the one in the middle)?

To get to the actual measurement of what a stimulus amounted to in sensation, Peirce divided the subject's answer in two parts. The first part would have been a "confidence disclaimer," in which the subject would state the degree of confidence (form 0 to 3 ) in his answer; only after that a judgement was required.

The idea behind this was that many stimuli, while not being consciously intuited, are nonetheless elaborated in sensation. According to Peirce, a work of unconscious comparison between the stimuli is performed in sensation before its result reaches consciousness and is expressed in judgement. From a philosophical perspective, this thesis had already been advocated by Peirce in the 1868 essays examined in section 1 . 
In 1885 , this thesis could be experimentally defended by showing that the judgements follow the statistical law of error even in cases in which they are pronounced with confidence $=0$. As Peirce writes,

[according to] the method of least squares, [...] the multiplication of observations will indefinitely reduce the error of their mean, so that if of two excitations one were ever so little the more intense, in the long run it would be judged to be the more intense the majority of times. ${ }^{56}$

If indeed there is an unconscious sensory discrimination between very small changes in the stimuli intensity, and if the conscious judgement is the result of a process of comparison and synthesis between small differences of sensation, this unconscious discrimination should be observable as affecting judgement in the long run. On the other hand, if, as Fechner's law maintains, there is a threshold beyond which no stimulus is perceived, the answers to stimuli below a certain limit intensity L should be purely random; that is to say, $50 \%$ wrong and $50 \%$ correct answers. This was precisely the result which Fechner obtained with his many experiments on sensation.

Peirce maintains that this result of Fechner is in part the product of a shortcoming in the method applied, reflecting Fechner's arbitrary choice to distribute the undecided answers equally between the right and wrong judgments ${ }^{57}$ moreover, Fechner was biased from knowing the right answer in advance. From his experiments, Peirce argues, something could eventually be learned about the ability to make comparisons and the grade of accuracy this ability could eventually reach. However, Fechner's method said nothing about what was in fact perceived, or about how the process of perception drew on the received stimuli. Indeed, according to Stigler (1986), the aim of Fechner's experiments was to ascertain the powers of judgement and not to describe the unconscious process of sensation:

Fechner's basic aim was to investigate how different factors affected the individual's sensitivity, that is, the accuracy of his judgment..$^{58}$

51 In contrast to this approach which uses psychophysics to investigate judgement, Peirce by 1883 was more and more tied to a physiologic interpretation of psychophysics. In the first chapter of his "On the Algebra of Logic" (1880) Peirce described nerves, sensory receptors, and "cerebration" as prospective beliefs, rules of action and of reasoning, thus tying together physiological descriptions with an account of "how logic itself arises." ${ }^{59}$ If in the fourth Illustration of the logic of science (1878) Peirce wrote that belief and evidence stand in the same relation in which sensation and stimulus stand, in 1880 Peirce defines belief as "a cerebral habit of the highest kind, which will determine what we do in fancy as well as what we do in action"60 and further emphasised the dependence of thinking on the brain:

Thinking, as cerebration, is no doubt subject to the general laws of nervous action. ${ }^{61}$

In the 1885 experiment, Perice's aim is therefore to show what the general law of this dependence may be. The results of Peirce and Jastrow are that, when undecided answers are not distributed equally between right and wrong cases and the subject is forced to pick an option and formulate a judgement, her answer would be right slightly more often than wrong ("three times out of five" ${ }^{\text {" }}$ ). This suggests that the difference between stimuli is in fact perceived even when we are unable to examine it consciously, and that its effect can be indirectly observed in the subsequent behaviour of the subject: not knowing why, she answers correctly. The result moreover is important in light of Peirce's philosophy because the 1885 experiment frames perception as an activity of comparison. A stimulus is not perceived in isolation, but always as "lesser" 
or "greater" in a set of stimuli. The unconscious process which informs the subsequent judgement is not to be seen as an unconscious contemplation of the singular stimulus by the senses, but as an unconscious inferential activity from a multiplicity of stimuli flowing in time. This result feeds into Peirce's contemporary theoretical attempts at explaining nervous action in terms of reflex action, irritation, and habit-taking. The epistemological structures of belief and doubt which had been introduced in the Illustrations series are now understood in relation to habit, and habit is in turn understood physiologically.

In the Illustrations, the whole business of the logic of science amounted to find a secure guide throughout inferences, a "leading principle" that could allow one to draw valid conclusions from her premises, i.e. to perform inferences whose conclusions are matched by facts. In "On the Algebra of Logic," the leading principle of inquiry is explained in terms of habit of thought; but thought in turn is subject to the laws of "nervous action" and seems therefore a far from an independent activity. Would every belief, as a habit in something being the case, end up being an expression of the relation between the intensity of a certain stimulus and our response to it? The ability to draw valid consequences in logic seems heavily dependant on how well shaped our habits are, i.e. how aptly our nerves react to the external stimuli that irritate them. This could easily lead to a deterministic view of inquiry, with the very process of thought determined physiologically. Peirce however does not invoke Fechenr's law as a way to measure the adaptive power of nerves. Instead, the principle to which his physiological machinery is oriented is the same that frames his fundamental hypothesis on science: his realism. The hypothesis that "there are real things" (1877: Fixation paper) and that physiological mechanisms of the body had to adapt in order to match the different stimuli they received from the external world is for Peirce one and the same with the possibility that an inquiry pursued long enough will eventually reach the truth:

Is there any law about the mode of the peripheral excitations? The logician maintains that there is, namely, that they are all adapted to an end, that of carrying a belief, in the long run, toward certain predestinate conclusions which are the same for all men. ${ }^{63}$

As Peirce defines it, the logician's interest in peripheral excitations is due to the fact that nerves are adapting their responses to the stimuli received from the outside, and the ability to adapt is also what is required for a belief to be true in the long run. It is the truth as the idea of an inquiry pursued long enough what orientates thought, and not the physiological responses themselves. However, beliefs converge to the truth of a state of affairs by undergoing the same process of inference and comparison that adapted nerves' responses to their stimuli. Beliefs and nervous excitations share the structure of their adaptive process because they are actually the same thing, only distinguished by degree. Belief is "a cerebral habit of the highest kind" but not qualitatively different from the automatic response of a reflex nerve. If this is the case, it becomes crucial, in order to have a material, effective logic, to understand how actually the stimuli are processed in the senses, and how far the senses can adapt. If Fechenr's model of a step-like relation between external stimuli and inner sensation is true, then Peirce would be forced to admit that there will always remain some discontinuity between the structure of reality and the structure of thought. If instead as the 1885 experiment suggests - judgement can adapt to changing stimuli in a continuous fashion, then there is potentially room for an infinite adjustment of our 
beliefs to the truth. Moreover, this physiological argument on the possibility of knowledge does not depend on the peculiar pattern that nerves take in every individual, but rather on what is common in nervous reaction and potentially includes all animal species with a nervous system. Therefore, Peirce's use of experimental psychology and physiology does not fall back into subjectivism.

\section{Conclusion} different scientific field and addresses the relation between the physical, the psychical, and rational thought. As was shown in $\$ 1$, this problem stems from postKantian debates on the nature of apperception and on the reality content of sensation. When Kant allows for the possibility that what is real in sensation is its "degree," i.e. its relational nature, its being understood only in the context of other sensations, Kant furnishes the following generation of Naturphilosophen and experimental philosophers with the opportunity to reach reality through experiments on sensation. The resulting science of psycho-physics is coming from a philosophical problem and can be resorted to for making claims upon the structure of reality and the possibility of achieving reliable knowledge of it. psycho-physics is actually, as the other physical sciences, a way of measuring what is "out there" and not an account of the intimate and private individual soul. The psychic is "out there" because it is built through comparison and inference from external stimuli; what may be "inner" in it is unconscious and can be measured indirectly as much as a physical force - e.g., gravity - can. This does not amount to a denial of inner experience, but only to the thesis that inner experience is of a derived and secondary kind, both regarding its being - it arises as the result of a clash between the inner intentions and the outer stimuli - and regarding our knowledge of it, since we have to 
reconstruct our inner states from their external manifestations (passions, opinions, beliefs, actions).

So far so good; but how should questions 3), 4) be answered in light of Peirce's philosophy? The questions were:

3) Are the laws according to which we reason also the laws according to which we ought to reason?

4) Do we need to model our normative prescriptions on a descriptive account of the mind?

The answer to questions 3) and 4) is not straightforward because Peirce, while rejecting traditional psychologism, is at the same time modifying the ground of the psychologism-antipsychologism debate to accommodate a view that does not fit into the traditional (i.e., post-Kantian) interpretation of this dichotomy to which we are accustomed today. In his view, the goal is not that of putting empirical research on the mind on the one side, and philosophical reflection upon reason on the other side, but rather that of having the two working together towards a common epistemic aim.

For Peirce, at least in the years 1869-85, the laws of reason (i.e., our normative prescriptions) are only in part different from the law according to which we reason (i.e., our descriptive statements). In fact, those two accounts of reasoning and thought share one important feature, i.e. the idea that all cognitive process - be it intellectual or sensory, conscious or unconscious - has an inferential structure. This proximity does not amount to reduction of one upon the other; nor does it explain away norms and prescriptions. In fact, the point of interest of Peirce's theory of reason lies in its ability to consider sensation and thought as two different but continuous parts of the rational growth of a living being. In doing this, Peirce is far from grounding logical laws on psychological research, and therefore far from psychologism as traditionally understood; however, his account of reason does not fit into a purely formal account of reason and of the scope of philosophy either. In 1903, Peirce describes this relation between philosophical inquiry and psychology with the image of a ring with no ground to rest upon:

[...] the philosophical sciences and psychology would have each to be built upon the other, if the psychological method is to be maintained. They must collectively form an arch - or, rather, a Saturn's ring, for an arch has the ground to rest upon. Whether that can be sound logic or not is a question to be carefully examined. ${ }^{65}$

Philosophy and psychology are cooperating across logic and the sciences to reach a unified account of thought. The study of arguments pursued by logic and the study of sensation pursued by psychology support each other in an attempt to reach a fully integrated account of cognition - a ring with no ground to rest upon, whose soundness is constantly open to inquiry. 


\section{BIBLIOGRAPHY}

AMBrosio C., (2016), "Composite Photographs and the Quest for Generality: Themes from Peirce and Galton," Critical Inquiry 42, 547-79.

ANDERSON D., (1995), Strands of System, Purdue University Press.

BAKER V.R. (ed.), (2013), Rethinking the Fabric of Geology, Geological Society of America.

BELLUCCI F., (2015), "Logic, Psychology, and Apperception: Charles S. Peirce and Johann

F. Herbart," Journal of the History of Ideas, 76 (1), 69-91.

BERKELEY G., (1710), An Essay Towards a New Theory of Vision. By George Berkeley (The second ed.), Dublin, Printed by Aaron Rhames, for Jeremy Pepyat.

BORING E.G.M.N., (1942), Sensation and Perception in the History of Experimental Psychology, New York, Appleton-Century-Crofts.

BREIDBACH O. \& M. T. GHISELIN, (2002), "Lorenz Oken and Naturphilosophie in Jena, Paris and London," Hist. Phil. Life Sci. 24, 219-47.

CADWALlAder T. C., (1974), “Charles S. Peirce (1839-1914): The First American Experimental Psychologist," Journal of the History of the Behavioral Sciences, 10 (3), 291-8.

CADWALLADER T. C., (1975), "Peirce as an Experimental Psychologist," Transactions of the Charles S. Peirce Society, 11(3), 167-86.

CLELAND C. E, (2001), "Historical Science, Experimental Science, and the Scientific Method," Geology, 29 (11), 987-90.

Colapietro V., (2003), “The Space of Signs: C. S. Peirce's Critique of Psychologism," in Philosophy, Psychology, and Psychologism. Critical and Historical Readings on the Psychological Turn in Philosophy, D. Jacquette ed., Philosophical Studies Series, 91, Dortrecht/Boston/London, Kluwer Academic Publishers, 157-79.

COON D. J., (1992), “Testing the Limits of the Sense and Science. American Experimental Psychologists Combat Spiritualism, 1880-1920," American Psychologist 47 (2).

DE TIENNE A., (1996), L'analytique de la représentation chez Peirce, Bruxelles, Publications des Facultés universitaires Saint-Louis.

DUARTE J. B., (1992), M. J. do Carmo Ferreira (ed.), Correspondencia Lambert/Kant (Book Review), Kant-Studien 83 (4), 474. [search.proquest.com/docview/1294191110?accountid=14511].

FABBRICHESI R. L., (2015), “L'orizzonte di una nuova antropologia pragmatica," in Su Peirce. Interpretazioni, ricerche, prospettive, a c. di Bonfantini M. \& Zingale S., Milano, Bompiani, 41-57.

FECHNER G. T., (1831), Massbestimmungen über die Galvanische Kette, Leipzig, Brockhaus.

FECHNER G. T., (1845), “Über die Verknüpfung der Faraday’schen Induktions-Erscheinungen mit dem Ampere'schen elektrodynamischen Erscheinungen," Annalen der Physik und Chemie 64, 337-45.

FECHNER G. T., (1860), Elemente der Psychophysik, 2 v., Leipzig.

FISCH M., (1986), “A Chronicle of Pragmaticism, 1865-79," in Peirce, Semeiotics, and Pragmatism, ed. by Ketner \& Kloesel. 
Giovanelli M., (2011), “Reality and Negation. Kant's Prinicple of Anticipations of Peirception. An Investigation of its Impact on the post-Kantian Debate," Studies in German Idealism 11, Springer. HACKING I., (1988), “Telepathy: Origins of Randomization in Experimental Design,” Isis, 79 (3), 427-51.

HOEL A. S., (2016), "Measuring the Heavens: Charles S. Peirce and Astronomical Photography," History of Photography, 40 (49).

HоOKWAY C., (1993a), "Belief, Confidence and the Method of Science," Transactions of the Charles S. Peirce Society, 29 (1), 1-32.

ноокWАY C., (1993b), “Mimicking Foundationalism: on Sentiment and Self-control," European Journal of Philosophy, 1 (2), 156-74.

KASSER J., (1999), "Peirce's Supposed Psychologism," Transactions of the Charles S. Peirce Society, 35 (3), 501-26.

MARShall M., (1982), "Physics, Metaphysics, and Fechner's Psychophysics," in Ash M. \&

Woodward W. R. (eds.), The Problematic Science. Psychology in Nineteenth Century Thought, New York, Praeger.

MARTINELli R., (1999), Misurare l'anima. Filosofia e psicofisica da Kant a Carnap, Macerata, Quodlibet. MISAK C., ([1991] 2004), Peirce and the End of Inquiry: A Peircean Account of Truth, Oxford, Clarendon Press.

MURPHEY M., (1961), The Development of Peirce's Philosophy, Cambridge, Mass., Harvard University Press.

NAYAK A.C. \& E. SOTNAK, (1995), "Kant on the Impossibility of the 'Soft Sciences'," Philosophy and Phenomenological Research, 55 (1), 133-51.

OKEN L., (1847), Elements of Physiophilosophy, trans. by Tuk A., London, Printed for the Ray Society. SCHELLING F., (1797), HKA 1:5:249. English translation by Harris \& Lauchlan 1988: Ideas for a Philosophy of Nature as Introduction to the Study of this Science, Cambridge University Press. STIGLER S. M., (1986), The History of Statistics. The Measurement of Uncertainty before 1900, New York, Belknap.

STAUBERMANN K., (2000), “The Trouble with the Instrument: Zöllner's Photometer,” Journal for the History of Astronomy, 31 (4), 323-38.

STURM T., (2001), "Kant on Empirical Psychology: How Not to Investigate the Human Mind," in Kant and the Sciences, Oxford University Press, Chapter 9.

STURM T., (2006), "Is There a Problem with Mathematical Psychology in the Eighteenth Century? A Fresh Look at Kant's old Argument," Journal of the History of the Behavioral Sciences 42, 353-77.

VASSALlo N., (1997), “Analysis versus Laws: Boole’s Explanatory Psychologism versus His Explanatory Anti-Psycholoigsm," History and Philosophy of Logic 18, 151-63.

wUNDT W., (1863), Vorlesungen über die Menschen- und Thierseele, Leipzig, L. Voss.

\section{APPENDIXES}

Peirce's Works: 
EP 1, followed by page number, for The Essential Peirce: Selected Philosophical Writings. Vol. 1, 1867-1893, ed. Nathan Houser and Christian Kloesel, (Indianapolis, Indiana University Press, 1992);

CN III, followed by page number, for Contributions to "The Nation." Vol. 3, ed. James Edward Cook and Kenneth Laine Ketner, Lubbock, Texas Tech University (1975).

W, followed by volume and page number, for Writings of Charles S. Peirce: A Chronological Edition, 8 vols., ed. Peirce Edition Project (Indianapolis, Indiana University Press, 1982-2009);

MS, followed by manuscript number and page number, for the unpublished manuscripts in the Houghton Library of Harvard University, as catalogued in Richard Robin's Annotated Catalogue of the Papers of Charles S. Peirce (Amherst, University of Massachusetts Press, 1967) and "The Peirce Papers. A Supplementary Catalogue," Transactions of the Charles S. Peirce Society 7 (1) (1971).

AA, Akademie Ausgabe Kants Gesammelten Werken, [korpora.zim.uni-duisburgessen.de/kant/verzeichnisse-gesamt.html].

\section{NOTES}

1. Vassallo (1997: 152).

2. W1, passim; Kasser (1999: 151).

3. Murphey (1961: 330).

4. Indeed, Hookway (1993b: 156) believes that "mimicking foundationalism [sic] and immediacy" is the way to justify knowledge without having to bear metaphysical costs, and that Peirce (1877) could help in this.

5. Kasser (1999: 502).

6. Kasser (1999: 516).

7. See Hacking (1988: 431), "Telepathy: Origins of Randomization in Experimental Design," Isis, 79 (3).

8. W3: 524: “On 25th October 1875 Peirce received two grants [...], one to study color $(\$ 1,200)$ and another to compare sensations (\$500)."

9. Fisch (W3: xxvii).

10. Fisch (1986: 119); Fisch's source is Peirce's correspondence.

11. Fisch (1986: 119-20).

12. EP1: 13.

13. W2: 502.

14. De Tienne (1996: 19-20).

15. W2: 502. Emphasis added.

16. EP1: 14-5. Emphasis of the text.

17. EP1: 15.

18. EP1: 15.

19. EP1: 5. De Tienne comments on this (1996, footnote 188): “Peirce écrit 'empirical psychology,' et on peut hésiter sur la meilleure manière de traduire l'adjectif. Expérimental semblerait s'imposer, mais il est peu probable que Peirce pensait réellement asseoir sa recherche sur le résultat d'expérimentations menées selon des rigoureux critères scientifiques." However, De Tienne does not provide an argument for this claim, limiting himself to assert that "La psychologie expérimentale était tout juste naissante à cette époque [...]." I will be content if this 
paper renders the connection between Peirce's early philosophical speculations and his interests in psychology at least less implausible.

20. W2: 94.

21. EP1: 5. Emphasis added.

22. EP1: 5.

23. Both the constructive and the general element of this process of comparison will remain crucial in Peirce's philosophy. Peirce's interest in Galton's use of "composite photographs" and his opposition to Galton's conclusions can be seen as yet another instance of this pictorial model of reasoning, which Peirce may have taken from geometry. For Peirce and Galton on composite photographs, see Ambrosio (2016: 565).

24. Kant, Metaphysical Foundations of Natural Science 4, 271: "Empirical psychology must always remain outside the rank of a natural science properly so-called" (trans. by Sturm 2001: 163).

25. Sturm (2006: 363-6).

26. See Nayak \& Sotnak (1995: 140).

27. Kant, KrV, A178-9/B221; Eng. trans. by Guyer \& Wood, 1998; emphasis added.

28. Fechner (1860: v): “Unter Psychophysik verstehe ich [...] eine exacte Lehre von den Beziehungen zwishen Leib und Seele [Under Psychophysics I understand [...] an exact science of the relations between Body and Mind]." Translation mine.

29. Marshall (1982: 66).

30. Fechner (1831), Maasbestimmungen über die galvanische Kette [Measurements of the Series of galvanic Cells]; see Marshall (1982: 66-7).

31. Marshall (1982: 68).

32. Marshall (1982: 70-1): "In 1845 Fechner published an atomic theory of electricity, a masterpiece of integration, in which he subsumed both Faraday's induction effects and Ampère's laws of electrodinamics." The referred paper is Fechner (1845), "Über die Verknüpfung der Faraday'schen Induktions-Erscheinungen mit dem Ampere'schen elektrodynamischen Erscheinungen."

33. Marshall (1982: 71).

34. Lorenz Oken (1847: 2), translated into English by Alfred Tulk. Oken's ideas circulated widely not only on the continent (Germany and France) but also in the British islands. See Breidbach \& Ghiselin (2002), "Lorenz Oken and Naturphilosophie in Jena, Paris and London."

35. Breidbach \& Ghiselin 2002.

36. HKA 1:5:249. English translation by Harris \& Lauchlan 1988: Ideas for a Philosophy of Nature as Introduction to the Study of this Science, 1797, Cambridge University Press. Emphasis added.

37. The relevance of old astronomical observations for contemporary research informs scientific practice also today. Significantly, this is now happening to Peirce's own work, with a project running in Harvard to digitalise the plate negatives of astronomy photographies from 1885 to 1989: "not for museum purposes, but in order to come alive again as a resource for present-day astronomical research." Hoel 2016, "Measuring the Heavens: Charles S. Peirce and Astronomical Photography," History of Photography, 40 (49).

38. For an overview of this complex debate, see Baker (ed.) (2013), Rethinking the Fabric of Geology, Geological Society of America; see also Cleland (2001), "Historical Science, Experimental Science, and the Scientific Method."

39. For a material history of the instrument, see Staubermann (2000), "The Trouble with the Instrument: Zöllner's Photometer."

40. Staubermann (2000: 323; 328).

41. Peirce (1878: 7; emphasis added).

42. Peirce PhR, 1878: 5.

43. Peirce (1878: 5 ).

44. W2: 350-1. 
45. W2: 351. Emphasis added.

46. W2: 349 .

47. For a thorough analysis on the belief/doubt role in the context of inquiry, and its relation to the possibility of obtaining truth, see Anderson (1995), Strands of System: The Philosophy of Charles Peirce.

48. EP1: 114.

49. EP1: 159.

50. EP1: 120. Emphasis added.

51. Joseph Jastrow will become president of the American Psychological Association in 1900. He is also the inventor of the duck-rabbit Gestalt figure made famous by Wittgenstein.

52. Coon (1992: 145): “The problem was that much of psychology's popular appeal lay in precisely those topics of its possible subject matter that many psychologists wanted to shed as pseudoscience - topics such as mental telepathy, clairvoyance, and spiritistic communication with the dead." In defence of a scientific study of telepathic phenomena there is the major case of William James.

53. W 5: 132; CP 7.32: "The first will include the experiments from December 10 to January 22, inclusive; the second from January 24 to February 24, inclusive; the third from March 4 to March 25 , inclusive; the fourth from March 30 to the end of the work."

54. Faribanks scales had an incredible diffusion in the post civil-war U.S., becoming an iconic measurement instrument. If interested in the material culture aspects of the story, a nonacademic source could be this: [theantiquesalmanac.com/ scientificinstrumentsreachforcollectibility.htm - sthash.9kGRQtHw.dpuf]. Pictures can be found here ([officemuseum.com/1883_Fairbanks_Postal_Office_Scale_adx.jpg]) and here ([officemuseum.com/1876_Fairbanks_scale_OMx.jpg]).

55. W 5: 130; CP 7.28.

56. W5: 123.

57. See Stigler (1986: 244; and 253 for Fechner's contemporaries' reactions to this choice).

58. Stigler (1986: 245).

59. EP1: 200.

60. EP1: 201.

61. EP1: 200.

62. W5: 135.

63. EP1: 202.

64. EP1: 212; "Introductory Lecture on the Study of Logic," 1882.

65. CN III: 128-9. Emphasis added.

\section{ABSTRACTS}

Charles Sanders Peirce was acknowledged by William James as the founder of pragmatism; however, while James' appreciation for psychology is well taken into account in his philosophy, the role that psychological inquiry played in Peirce's thought remains largely unexplored. Few excellent studies indicate Peirce as the first American experimental psychologist (Cadwallader 1974, 1975; Fisch 1986) and as the first to perform a truly modern experiment in psycho-physics (Hacking 1988). Nonetheless, Peirce's commitment to psycho-physics fails to be fully integrated 
with the broader project of his philosophy. This integration is crucial to gain a better understanding of the complexity of Peirce's system of thought and of his position in the psychologistic-antipsychologistic divide. On the logical side, making Peirce's position on psychology explicit leads to investigating his material logic; on the psychological side, Peirce's scientific approach to psychology has its theoretical foundation in Kant and further marks the distinction between Peirce's pragmatism and James'.

\section{AUTHOR}

\section{CLAUDIA CRISTALLI}

University College London

claudia.cristalli.15[at]ucl.ac.uk 